\title{
Neurotoxicity after liver transplantation: does donor age matter?
}

\author{
Lydia Sastre, Gonzalo Crespo \\ Liver Unit, Hospital Clínic, Institut d'Investigacions Biomèdiques August Pi I Sunyer (IDIBAPS), Centro de Investigación Biomédica en Red de \\ Enfermedades Hepáticas y Digestivas (CIBERehd), University of Barcelona, Barcelona, Spain \\ Correspondence to: Gonzalo Crespo, MD. Liver Unit, Hospital Clinic, IDIBAPS, CIBERehd, University of Barcelona, Villarroel 170, Barcelona \\ 08036, Spain. Email: gcrespo@clinic.cat. \\ Comment on: Lué A, Martinez E, Navarro M, et al. Donor Age Predicts Calcineurin Inhibitor Induced Neurotoxicity After Liver Transplantation. \\ Transplantation 2019;103:e211-e215.
}

Received: 29 November 2019; Accepted: 15 January 2020; Published: 25 October 2021.

doi: $10.21037 /$ tgh.2020.01.03

View this article at: http://dx.doi.org/10.21037/tgh.2020.01.03

Early calcineurin inhibitors (CNIs)-induced neurotoxicity is a serious and frequent complication after liver transplantation (LT). It takes place in $6-47 \%$ of LT recipients treated with $\mathrm{CNI}$, and it is associated with significant mortality, morbidity, and prolonged hospital stay (1-3). Controversy continues over which patients have a greater risk of developing CNI neurotoxicity after LT (4). The incidence of early CNI neurotoxicity is higher in LT recipients receiving tacrolimus compared with patients receiving cyclosporine (5). Major central nervous system manifestations are diverse, and they are commonly classified as minor (tremor, headache, insomnia, paresthesia), and major (encephalopathy, akinetic mutism, seizures, speech disorders, polyneuropathy, psychosis) (3). Different ways of treating early CNI neurotoxicity have been described, such as a decrease in the dosage of CNI using other immunosuppressant drugs (mycophenolate mofetil or everolimus), switching from tacrolimus to cyclosporine or vice versa, and even CNI withdrawal in the most severe cases (2).

Several retrospective studies have investigated the risk factors and possible mechanism of CNI neurotoxicity. Most studies have focused on recipients' risk factors: age, MELD score, ALT, bilirubin, creatinine, glycemia, hypocholesterolemia, hyponatremia, hypomagnesemia, hypertension, alcohol consumption and hepatic encephalopathy $(2,3,6)$ have been shown as potential risk factors for CNI neurotoxicity. In addition, Yamauchi et al. described that a polymorphism in the ABCB1 gene may be a risk factor for tacrolimus induced neurotoxicity in related living donor LT recipients (7). However, few studies have evaluated donor and technical aspects as potential risk factors for CNI-neurotoxicity in liver transplant recipients $(8,9)$.
In their recent article, Lué et al. found that donor age, higher pre-LT sodium levels and previous history of hepatic encephalopathy are independent predictors of CNI neurotoxicity after LT (8). The authors designed a retrospective single-center study with 175 LTs performed in 162 patients in Spain between January 2010 and September 2016. CNI neurotoxicity was described in 37 (21.4\%) LT recipients at a median time of 3 days (range, 2-5 days) post-LT. Patients with CNI neurotoxicity had a higher incidence of past history of hepatic encephalopathy $(67.6 \%$ vs. $47.8 \%, \mathrm{P}=0.033)$, higher pre-LT serum sodium levels $(137.84 \pm 5.23$ vs. $135 \pm 5.31 \mathrm{mEq} / \mathrm{L}, \mathrm{P}=0.004)$, and received a standard immunosuppressant regimen (early introduction of CNI) less frequently ( $75 \%$ vs. $83 \%, \mathrm{P}=0.041)$. In addition, patients in the CNI neurotoxicity group had received their grafts from significantly older donors $(65.62 \pm 14.38 \mathrm{vs}$. $56.82 \pm 15.69, \mathrm{P}=0.002)$. There were no differences between the two groups in terms of recipients' age and gender, and the authors performed center-directed allocation without donor-recipient matching.

Differently to previous publications that found an association between post-LT hyponatremia and CNI neurotoxicity (3), the authors could not show significant differences in post-LT sodium levels between both groups (8). On the other hand, higher pre-LT sodium serum levels (OR 1.118, 95\% CI: $1.021-1.224$; $\mathrm{P}=0.016$ ) were an independent predictor of CNI neurotoxicity (8). This is in contrast with other studies that suggested a relationship between pre-LT hyponatremia and the development of post-LT neurological complications, mainly central pontine myelinolysis $(6,10)$, thus these results are surprising. Authors hypothesize that 
this could be explained by the fact that patients received different immunosuppressive protocols after LT: patients with more advanced liver disease, impaired renal function or hepatorenal syndrome (thus those more prone to hyponatremia) received delayed and low doses of tacrolimus after LT, potentially decreasing the chances of these patients of suffering CNI neurotoxicity. Despite this may partially put into perspective these findings, the potential association between higher (albeit normal) sodium levels and post-LT neurotoxicity remains to be completely understood.

With respect to the role of donor age, there are few data on its impact on neurotoxicity, and the mechanisms by which donor age would affect CNI neurotoxicity have not been investigated. Hypothetically, it may be related to a lower capacity of older livers of metabolizing such drugs. Lué et al.'s results could be partially in line with those described by $\mathrm{Wu}$ et al., who reported that donor age $<22$ or $\geq 40$ years and graft-recipient weight ratio are associated with neurological complications after LT (9). In this study, that included 295 adult LT recipients (193 of whom received their grafts from living donors), the incidence of neurological complications was $49.3 \%$, with encephalopathy being the most common complication ( $\mathrm{n}=106,73 \%)$. Risk factors for neurological complications included alcoholrelated cirrhosis, more severe liver disease (MELD score: $20.3 \pm 9.4$ vs. $14 \pm 7.4, \mathrm{P} \leq 0.0001$ ), history of encephalopathy (91 vs. 41, $\mathrm{P} \leq 0.0001)$ and mental disorders (66 vs. 33, $\mathrm{P} \leq 0.0001)$ and a higher day 7 tacrolimus level $(8.23 \pm 7.42$ vs. $6.54 \pm 4.69, \mathrm{P}=0.023)$. Focusing in donors' perspective, extreme donor age, male-to-male gender matching and graft recipient weight ratio $0.9-1.9 \%$ were risk factors for neurological complications. Considering this, it may appear that donor-related factors like age and genetics could directly impact the risk of development of CNI neurotoxicity. Unfortunately, genetic or pharmacokinetic factors could not be measured, which could have added to the knowledge of the mechanisms and pathophysiology of CNI neurotoxicity in liver transplant recipients, an issue that is still to be investigated in depth.

Despite its limitations, the study by Lué et al. may be of clinical relevance. In the current setting of a general decrease in LT wait-listing as a consequence of the high efficacy of antiviral therapy with direct-acting antivirals against hepatitis $C$ virus, together with a higher tendency to include in the waiting list patients with more comorbidities (including cardiovascular risk factors), acuteon-chronic liver failure or acute alcoholic hepatitis (these two latter groups of patients with high MELD scores), the postoperative outcomes, including neurotoxicity, may differ and become more relevant. In this regard, the results of the study may help to consider the allocation of donor livers according to post-LT risks, taking into account other recipient characteristics such as age, sodium levels or MELD score. However, it is clear that these results must be interpreted with caution. The retrospective design of the study, a small sample size, and the characteristics of the cohort (including a population with low MELD score); together with the absence of a detailed description of CNI levels and dosing are limitations of the study that need to be taken into account. Notwithstanding, this study may lead to the design of large series of case-control studies to validate the results, and, in the end, contribute to donor-recipient matching in LT, which may eventually improve the results of LT. In this regard, next research in this topic may be related to prospectively evaluate the effect of donor age in a-priori defined neurotoxicity in larger cohorts, to confirm the results of the present study.

In the end, the study by Lue et al. can be of relevance in the field of LT, although new studies are required in order to confirm their results and overcome its limitations.

\section{Acknowledgments}

Funding: None.

\section{Footnote}

Provenance and Peer Review: This article was commissioned by the editorial office, Translational Gastroenterology and Hepatology. The article did not undergo external peer review.

Conflicts of Interest: Both authors have completed the ICMJE uniform disclosure form (available at http://dx.doi. org/10.21037/tgh.2020.01.03). The authors have no conflicts of interest to declare.

Ethical Statement: The authors are accountable for all aspects of the work in ensuring that questions related to the accuracy or integrity of any part of the work are appropriately investigated and resolved.

Open Access Statement: This is an Open Access article distributed in accordance with the Creative Commons Attribution-NonCommercial-NoDerivs 4.0 International License (CC BY-NC-ND 4.0), which permits the non- 
commercial replication and distribution of the article with the strict proviso that no changes or edits are made and the original work is properly cited (including links to both the formal publication through the relevant DOI and the license). See: https://creativecommons.org/licenses/by-nc-nd/4.0/.

\section{References}

1. Souto-Rodríguez R, Molina-Pérez E, Castroagudín JF, et al. Differences in the incidence and clinical evolution of early neurotoxicity after liver transplantation based on tacrolimus formulation used in the immunosuppressive induction protocol. Transplant Proc 2014;46:3117-20.

2. Guarino M, Benito-Leon J, Decruyenaere J, et al. EFNS guidelines on management of neurological problems in liver transplantation. Eur J Neurol 2006;13:2-9.

3. Balderramo D, Prieto J, Cárdenas A, et al. Hepatic encephalopathy and post-transplant hyponatremia predict early calcineurin inhibitor-induced neurotoxicity after liver transplantation. Transpl Int 2011;24:812-9.

4. Piñero F, Mendizabal M, Quiros R, et al. Neurological events after liver transplantation: a single-center

\section{doi: $10.21037 / \operatorname{tgh} .2020 .01 .03$}

Cite this article as: Sastre L, Crespo G. Neurotoxicity after liver transplantation: does donor age matter? Transl Gastroenterol Hepatol 2021;6:66. experience. Transpl Int 2014;27:1244-52.

5. Bechstein WO. Neurotoxicity of calcineurin inhibitors: impact and clinical management. Transpl Int 2000;13:313-26.

6. Londoño MC, Guevara M, Rimola A, et al. Hyponatremia impairs early posttransplantation outcome in patients with cirrhosis undergoing liver transplantation.

Gastroenterology 2006;130:1135-43.

7. Yamauchi A, Ieiri I, Kataoka Y, et al. Neurotoxicity induced by tacrolimus after liver transplantation: relation to genetic polymorphisms of the ABCB1 (MDR1) gene. Transplantation 2002;74:571-2.

8. Lué A, Martinez E, Navarro M, et al. Donor Age Predicts Calcineurin Inhibitor Induced Neurotoxicity After Liver Transplantation. Transplantation 2019;103:e211-e215.

9. Wu SY, Chen TW, Feng AC, et al. Comprehensive risk assessment for early neurologic complications after liver transplantation. World J Gastroenterol 2016;22:5548-57.

10. Lee J, Kim DK, Lee JW, et al. Rapid correction rate of hyponatremia as an independent risk factor for neurological complication following liver transplantation. Tohoku J Exp Med 2013;229:97-105. 